Thomas MormanN

\title{
TOPOlOGY AS AN IsSUe FOR History of Philosophy of Science
}

\begin{abstract}
Since antiquity well into the beginnings of the 20th century geometry was a central topic for philosophy. In contrast, most philosophers of science, if they took notice of topology at all, considered it as an abstruse subdiscipline of mathematics lacking philosophical interest. Here it is argued that this neglect of topology may be conceived of as the sign of a conceptual sea-change in philosophy of science that expelled geometry, and, more generally, mathematics, from its central position in philosophy of science and, instead, placed logic at center stage in the 20th century philosophy of science. Only in recent decades logic has begun to loose its monopoly and geometry and topology received a new chance to find a place in philosophy of science, as an object for philosophical reflection and as a conceptual tool for doing philosophy.
\end{abstract}

\section{INTRODUCTION}

From antiquity to the beginnings of the $20^{\text {th }}$ century philosophers took geometry as the paradigmatic example of science. Geometry defined what was to be considered as scientific knowledge. "More geometrico" was considered as a sign of quality for philosophical and scientific argumentation. At the beginning of the $20^{\text {th }}$ century, the privileged philosophical status of geometry seemed to be as solid as it always had been. For philosophers such as Russell, Cassirer or Carnap, to name but a few, philosophical problems posed by geometry played a central role in their investigations - at least at the beginnings of their careers:

(i) Russell started his philosophical career in 1897 with the dissertation The Foundations of Geometry. ${ }^{1}$ A few years later, in The Principles of Mathematics he treated themes from geometry at great length. ${ }^{2}$ In The Analysis of Matter Russell was engaged in using topological methods for the "logical analysis" of space and time. $^{3}$

1 Bertrand Russell, The Foundations of Geometry. Cambridge: Cambridge University Press 1897.

2 Bertrand Russell, The Principles of Mathematics. Cambridge: Cambridge University Press 1903.

3 Bertrand Russell, The Analysis of Matter. London: Routledge 1927. 
(ii) Throughout his life, Cassirer considered Klein's Erlangen Programme as a guideline for the epistemology of his "Critical Idealism" characterizing the task of epistemology as finding the ultimate invariants of scientific knowledge. In Substanzbegriff und Funktionsbegriff and much later in The Philosophy of Symbolic Forms he dedicated central chapters to concept formation in geometry which he considered as a paradigmatic case for concept formation in science überhaupt. ${ }^{4}$

(iii) Carnap's first philosophical publication was his dissertation Der Raum. Ein Beitrag zur Wissenschaftslehre. ${ }^{5}$ There he sought to establish the topological structure of space as a modernized version of a Kantian synthetic a priori. Moreover, the geometrical considerations of this work may be regarded as an important source for his later philosophy. ${ }^{6}$

The high esteem of $20^{\text {th }}$ century philosophy of science for geometry and, more generally, for mathematics, went well beyond the philosophical currents that in the following decades were to form analytic philosophy of science. For instance, also in phenomenology great emphasis was put on geometry as a paradigmatic example of scientific knowledge. This is evidenced not only by the work of Husserl himself but also by the contributions to a phenomenological philosophy of mathematics by mathematicians and philosophers such as Hermann Weyl, Dietrich Mahnke or Oskar Becker. ${ }^{7}$ The same holds for some currents of Neokantian philosophy of science, for instance, the Marburg school of Neokantianism whose members, such as Hermann Cohen, Ernst Cassirer, and Paul Natorp, emphasized the role of mathematics in many works.

In sum, in the early decades of the last century, geometry certainly did not belong to the sciences "neglected by received philosophy of science" - on the contrary, at that time geometry was one of the hot topics of received philosophy of science.

4 Ernst Cassirer, Substanzbegriff und Funktionsbegriff: Untersuchungen über die Grundfragen der Erkenntniskritik. Berlin: Bruno Cassirer 1910, trans. Substance and Function. Chicago and LaSalle: Open Court 1923; Philosophie der symbolischen Formen, 3 vols., Berlin: Bruno Cassirer 1923-29, trans. The Philosophy of Symbolic Forms. New Haven: Yale University Press 1953.

5 Rudolf Carnap, Der Raum. Ein Beitrag zur Wissenschaftslehre Kantstudien Ergänzunghefte 56, 1922.

6 See Thomas Mormann, "Geometrical Leitmotifs in Carnap's Early Philosophy", in: Michael Friedman, Richard Creath (Eds.), The Cambridge Companion to Carnap. Cambridge: Cambridge University Press 2007, pp. 43-64.

7 Hermann Weyl, Das Kontinuum, 1919, transl. The Continuum. New York: Dover 1994. Dietrich Mahnke, "From Hilbert to Husserl: First Introduction to Phenomenology, Especially that of Formal Mathematics". Translated by D. Boyer. Studies in the History and Philosophy of Science 8, 1977, pp. 71-84 (orig. 1923). Oskar Becker, "Beiträge zur phänomenologischen Begründung der Geometrie und ihrer physikalischen Anwendungen”, in: Jahrbuch für Philosophie und phänomenologische Forschung 4, 1923 , pp. $385-560$. 
This was soon to change, however. While geometry as a methematical discipline experienced a golden age during the $20^{\text {th }}$ century mathematics, it lost its privileged status in philosophy. This became apparent first by the fact that traditional geometry's most promising offspring - topology - fell into philosophical disregard. The philosopher's traditionally high appreciation of geometry did not extend to topology as its modern successor. On the contrary, in the $20^{\text {th }}$ century topology may be rightly characterized as a science "neglected by received philosophy of science". Even more, the philosophical neglect of topology was just the harbinger of a fundamental sea-change in philosophy of science, namely, the substitution of geometry, and more generally of mathematics, as a core issue of philosophy of science, by logic. Painted with a broad brush the $20^{\text {th }}$ century mainstream logical empiricist $20^{\text {th }}$ century philosophy of science was a logic-centered philosophy of science, concentrating on logical questions concerning the logical structure of science. ${ }^{8}$

Since from the mathematical point of view there is no essential epistemologi$\mathrm{cal}$, ontological, or methodological difference between geometry and topology, the negligible amount of attention that philosophy paid to topology in the last century must be attributed to a change in the way philosophers understood the aims and methods of philosophy of science. This renders philosophy's neglect of topology an intricate problem for the history of philosophy of science.

For the following it is useful to distinguish between two different aspects according to which the relations between traditional philosophy and geometry on the one hand, and between $20^{\text {th }}$ century philosophy and topology on the other, differed from each other:

First, $20^{\text {th }}$ century philosophy of science showed no interest in topology as an object of philosophical reflection. There has been no "philosophy of topology" in analogy to disciplines such as "philosophy of physics", "philosophy of biology", or "philosophy of geometry" (as it existed as a living philosophical discipline till the beginning of the last century). Second, traditionally geometry had also served as a source for inspiration and as an arsenal of conceptual tools for philosophy itself. This fruitful exchange did not find a continuation between the $20^{\text {th }}$ century philosophy of science and topology. Ideas from topology hardly found their way in the conceptual tool kit of the philosopher of science.

8 During the decades the concentration of philosophy of science on the logical aspects of science was assessed quite differently: In the 1930s we find Carnap's sweeping claim that "philosophy of science just is logic of science". At the end of the $20^{\text {th }}$ century Carnap's thesis had lost some of its appeal - to put it mildly. Van Fraassen put forward the harsh verdict: "It was a tragedy for philosophers of science to go off on these logicolinguistic tangles, which contributed nothing to the understanding of either science or logic or language." (Bas C. van Fraassen, Laws and Symmetry. Oxford: Clarendon Press 1989, p. 221). This is not to say that the use of mathematics provides a foolproof method for doing substantial philosophy of science. 
My thesis is that this twofold neglect of topology by philosophy of science was just the first sign of a fundamental sea-change in philosophy of science, namely, the replacement of mathematics as a guiding science for philosophy by logic. Although the core disciplines of science were mathematized sciences, mainstream philosophy of science was to treat science from an exclusively logical point of view. The disregard of mathematical, in particular geometrical and topological, aspects of science by philosophers of science was in stark contrast to the emphasis that they put on the logical aspects of the scientific enterprise.

\section{TOPOLOGY AS A PROBLEM FOR PHILOSOPHY OF SCIENCE}

What is topology? It goes without saying that a short paper like this is not the appropriate place for answering this question. ${ }^{9}$ As a mathematical discipline in its own right, recognizable also for non-mathematicians, topology came into being around the turn of the last century. Let us mention the names of Cantor, Poincaré, Frechet, and Hausdorff, to name just a few of the leading figures. Topological ideas and problems may be traced back, however, to Leibniz and Euler: One may think of the famous "Seven bridges of Königsberg" or "Euler's theorem" dealing with the relation between the vertices, edges, and faces of polygons, from which Lakatos squeezed so much juice for philosophy of mathematics. ${ }^{10}$

In broadest outline, then, topology is concerned with the conceptual analysis of spatial notions, such as "space in general", "connectedness", "neighborhood", "approximation", "convergence", "continuity", "mappings", "transformations", "boundedness", and many others. Evidently, these concepts may have had their origin in our daily experiences with physical space but they make sense far beyond the original Euclidean frame.

A first step to overcome the traditional Euclidean conception of space was to consider general metrical spaces:

(2.1) Definition. A metrical space $(\mathrm{X}, \mathrm{d})$ is a set of points endowed with a distance function $\mathrm{d}: \mathrm{X} \times \mathrm{X} \rightarrow \mathbf{R}$ ( $\mathbf{R}$ the real numbers) satisfying the axioms:

9 The reader may find some preliminary answers of this question especially adapted to the needs of philosophers in papers by Franklin and by Grosholz (Philip Franklin, „What is Topology?", in: Philosophy of Science 2, 1935, pp. 39-47; Emily Grosholz, "Two Episodes in the Unification of Logic and Topology", in: The British Journal for the Philosophy of Science 36, 1985, pp. 147-157.), or in the monographic issue of The Monist, "Topology for Philosophers" (Barry Smith and Wojciech Zelaniec (Eds.), Topology for Philosophers, The Monist 79(1). 1996). Stephen Willard, General Topology. New York: Dover 2004 (orig. 1970) offers a classical introduction for mathematically interested readers.

10 Imre Lakatos, Proofs and Refutations. Cambridge: Cambridge University Press 1976. 
(i) $\mathrm{d}(\mathrm{x}, \mathrm{x})=0$.

(ii) $\mathrm{x} \neq \mathrm{y} \Rightarrow \mathrm{d}(\mathrm{x}, \mathrm{y})=\mathrm{d}(\mathrm{y}, \mathrm{x})>0$.

(iii) $\mathrm{d}(\mathrm{x}, \mathrm{y})+\mathrm{d}(\mathrm{y}, \mathrm{z}) \geq \mathrm{d}(\mathrm{x}, \mathrm{z})$ (Triangle Inequality).

The requirements (2.1) (i) and (ii) may be considered as almost analytical for any reasonable notion of distance, while (2.1) (iii) rather faithfully reflects a property of the Euclidean distance function.

A further, more radical step away from traditional geometry toward topology in its proper sense, was the generalization from metrical to general topological spaces that freed the topological, i.e. the spatial, from any vestige of a quantitative metric or distance function.

In the literature a variety of equivalent definitions of a topological space exists. Arguably, the following is the most common one:

(2.2) Definition. Let $\mathrm{X}$ be a set and denote by $\mathrm{PX}$ the power set of all subsets of $\mathrm{X}$. A topological space $(X, O X)$ is defined as a set $X$ with a class $\mathrm{OX} \subseteq \mathrm{PX}$, called the open sets of the topological space, that satisfy the following requirements:

(i) $\mathrm{X}$ and the empty subset $\varnothing$ are open sets.

(ii The union of any collection of open sets is open.

(iii) The intersection of two open sets is open.

$\mathrm{OX}$ is called a topology or a topological structure on $\mathrm{X}$.

A metrical space $(\mathrm{X}, \mathrm{d})$ such as the Euclidean space is rendered a topological space by defining the metrical topology as the one that is generated by the "open balls":

$$
\mathrm{U}(\mathrm{x}, \varepsilon):=\{\mathrm{y} ; \mathrm{d}(\mathrm{x}, \mathrm{y})<\varepsilon, \mathrm{x} \in \mathrm{X} \text { and } \varepsilon>0\} .
$$

It should be noted that in general a set $X$, in particular the set of points of Euclidean space, can be endowed with many different topological structures OX. Among the many possible topologies on a set $\mathrm{X}$ one may mention the coarsest topology defined as $\mathrm{O}_{0} \mathrm{X}=\{\varnothing, \mathrm{X}\}$ and the discrete topology defined as $\mathrm{O}_{1} \mathrm{X}=\mathrm{PX}$. All other topologies OX on X are "between" these two extreme topologies. More precisely, the topologies OX on X can be partially ordered by set-theoretical inclusion:

$$
\{\varnothing, \mathrm{X}\}=\mathrm{O}_{0} \mathrm{X} \subseteq \mathrm{OX} \subseteq \mathrm{O}_{1} \mathrm{X}=\mathrm{PX}
$$

It would be an egregious error to take the profusion of possible topologies OX on $\mathrm{X}$ as evidence that the concept of topology is arbitrary and therefore trivial. The point of defining a topological structure on a set $\mathrm{X}$ is not to define just any one, but rather to define an interesting one. What is to be considered as an interesting topological structure highly depends on the specifics of the situation. It requires considerable skill and mathematical ingenuity to find "good" topologizations and to exploit them in a fruitful manner. 
One of the early masters of this "art of topologizing" was the American mathematician Marshall H. Stone who obtained spectacular results by applying the new topological devices in many areas of mathematics, in particular in lattice theory and functional analysis. ${ }^{11}$ Stone coined the maxim "You must always topologize". ${ }^{12}$ He conceived of topology as a universal method or perspective from which every mathematical problem should be looked at, i.e. all objects should be considered as topological ones. The topological was a kind of a general a priori form, under which mathematical objects and relations were to be perceived in order to reveal their essential aspects.

Perhaps one may say that Stone sought to conceive of topology as a generalized "transcendental aesthetics" roughly in Kant's sense, based on a general topological a priori. The fruitfulness of Stone's topological was amply demonstrated in many areas of $20^{\text {th }}$ century mathematics. ${ }^{13}$ Nevertheless, among philosophers his work has remained virtually unknown up to this day.

Since the axioms for a topological structure are extremely general, it is not to be expected that from them strong specific results can be obtained. Rather, an important task of topology is to single out appropriate special classes of topological spaces for which one can prove more specific results. For instance, the already mentioned metrical spaces are an important class, metrizable spaces and Hausdorff spaces provide more general classes, among many others. ${ }^{14}$

Studying a topological space in isolation seldom yields interesting results. Rather, relations between topological spaces are of crucial importance. Hence the second fundamental concept of topology, which has to be mentioned, is that of a continuous map between spaces:

(2.3) Definition. Given two topological spaces $\mathrm{X}$ and $\mathrm{Y}$ a set-theoretical map $\mathrm{X}-\mathrm{f} \rightarrow \mathrm{Y}$ is called continuous (with respect to the topologies $\mathrm{OX}$ and $\mathrm{OY}$ defined on $\mathrm{X}$ and $\mathrm{Y}$, respectively), if and only if for every $\mathrm{B} \in \mathrm{OY}$ the inverse image $\mathrm{f}^{-1}(\mathrm{~B})$ $=\{\mathrm{a} ; \mathrm{f}(\mathrm{a}) \in \mathrm{B}\}$ is an element of OX. Roughly, then, (set-theoretical) topology may be described as the theory of topological spaces and continuous maps between topological spaces."

After these preparations some important general types of topological problems may be described as follows:

11 Marshall H. Stone, "The Theory of Representations for Boolean Algebras", in: Transactions of the American Mathematical Society 44, 1936, pp. 807-816.

12 Mario Piazza, "'One Must Always Topologize'”: Il teorema di Stone, la 'topologia influente' e l'epistemologia matematica", in: Rivista di storia della scienza (ser. II) 4, 1995, pp. 1-24.

13 Peter Johnstone, Stone Spaces. Cambridge: Cambridge University Press 1982.

14 For a comprehensive classification of types of topological spaces and their logical relations the reader may consult the very useful compilation in Lynn Arthur Steen, J. Arthur Seebach Jr., Counterexamples in Topology. New York: Springer 1978. 
(i) Given topological spaces $\mathrm{X}$ and $\mathrm{Y}$, can one prove (or disprove) that they are "equivalent" in a sense to be specified?

(ii) Given topological spaces $\mathrm{X}$ and $\mathrm{Y}$, does there exist a non-trivial continuous map $\mathrm{X}-\mathrm{f} \rightarrow \mathrm{Y}$ ?

(iii) Can one find interesting invariants that can be calculated to characterize topological spaces in an efficient way (e.g. fundamental groups, higher homotopy groups, (co-) homology theories)?

For many, apparently “elementary” spaces these problems are still unsolved today.

\section{Philosophers and topology: Some examples}

Let us now briefly mention some of the few philosophical attempts to come to terms with topology. The most important example is certainly Russell but he was not the only philosopher who was interested in topology. For instance, Carnap in his dissertation Der Raum had proposed to save a Kantian synthetic a priori of space by conceiving of the metrical structure of space as a mere convention but retaining the topological structure of Euclidean space as a core a priori. This proposal seems not to have impressed his fellow philosophers. Moreover, Carnap himself gave it up soon after the publication of Der Raum. In the Aufbau traces of topology are still noticeable, but in his later work in philosophy of science topology and geometry does no play a role at all. ${ }^{15}$ Cassirer emphasized in his philosophy of science the importance of geometry for philosophy of science, but offered only some general, passing remarks on the role of topology. ${ }^{16}$ Compared with Carnap's and Cassirer's remarks Russell's topological project was by far as the most sustained and detailed one. Russell developed his topological ideas with various degrees of precision and explicitness in several contributions, beginning with Our Knowledge of the External World, later in a more detailed way in The Analysis of Matter, and finally in On Order in Time. ${ }^{17}$ Indeed, Russell sought to use the methods of topology for the core task of scientific philosophy, to wit, for logical analysis.

According to Russell the aim of logical analysis was the elimination of suspicious or otherwise undesired entities from philosophical discourse. In Our Knowledge of the External World he sought to show by means of examples,

15 See Mormann, op. cit.

16 See Cassirer, Philosophy of Symbolic Forms, op. cit., pp. 422-423.

17 Bertrand Russell, Our Knowledge of the External Worlds as a Field for Scientific Method in Philosophy. London: Routledge and Kegan Paul 1914; The Analysis of Matter, op. cit.; "On Order of Time", in: Russell, Logic and Knowledge. London: Routledge 1956, pp. 347-363 (orig. 1936). 
the nature, capacity, and limitations of the logical-analytic method in philosophy. ... The central problem by which I have sought to illustrate method is the problem of the relation between the crude data of sense and the space, time and matter of mathematical physics. ${ }^{18}$

In other words, Russell proposed to apply topology as a means for the solution of a genuine philosophical problem, namely, the logical analysis and the elucidation of the complex relation between sense data and the mathematical conceptualizations of physics.

More precisely, Russell wanted to show that the basic mathematical structures of physical space-time - usually conceived of as structured sets of spatial and temporal points (instants) - could be logically reconstructed from 'crude sense data', later to be characterized as 'events'. He credited Whitehead with the basic ideas of this approach:

I owe to Dr. Whitehead the definition of points, the suggestion for the treatment of instants and "things", and the whole conception of the world of physics as a construction rather than an inference. What is said on these topics here is, in fact, a rough preliminary account of the more precise results which he is giving in the fourth volume of our Principia Mathematica. ${ }^{19}$

Regrettably, the announced fourth volume of Principia Mathematica never saw the light of the day. In Process and Reality Whitehead put forward something like a topological philosophy, but it was not more than a sketch and had no influence on mainstream analytic philosophy of science.

A more detailed account of the construction of points can be found in The Analysis of Matter; Russell's last original work on the matters of points (more precisely on temporal points, i.e. instants) was "On Order in Time". For instants as well as for spatial points Russell used the same constructional method. His paper opens with the following contention:

[I]nstants are mathematical constructions, not physical entities. If, therefore, there are instants, they must be classes of events having certain properties. For reasons explained in Our Knowledge of the External World, pages 116-120, an instant is most naturally defined as a group of events having the following two properties:

(1) Any two members of the group overlap in time, i.e. neither is wholly before the other.

(2) No event outside the group overlaps with all of them. ${ }^{20}$

Intuitively, Russell's sketchy construction of an instant may be described as an "onion construction", i.e., Russell defines an instant as the limit of a nested collection of temporal intervals. In modern terms, Russell's construction resembles a construction of instants by maximal filters. In mathematically rigorous terms, such

18 Bertrand Russell, Our Knowledge of the External World, op. cit., p. 10.

19 Ibid., pp. 10-11.

20 Bertrand Russell, "Order in Time", op. cit., p. 347. 
constructions were carried out by Tarski and Stone around the same time. The crucial point in this construction was the existence of maximal filters (ultra-filters). Their existence can only be ensured by the axiom of choice or a similar principle as also Russell had noted. In other aspects, however, Russell's constructions remained vague and even seem to be mathematically flawed in some respects. ${ }^{21}$

Evidence that philosophy of science had actually lost contact with topology was that neither Russell nor any other philosophers of science ever took notice of the path-breaking work of the American mathematician Marshall H. Stone who in the 1930s proved one the most important theorems of the $20^{\text {th }}$ century mathematics, to wit, Stone's representation theorem. This theorem established surprising and deep relations between logic and topology, and it could have easily been used to secure what Russell sought to achieve, namely the construction of (temporal and spatial) points from temporal intervals and spatial points from spatial regions.

Despite his prominence as a philosopher, Russell's excursions into topology did not arouse much interest among his colleagues. In the following decades philosophers now and then paid due reference to the later Russell's talent for dealing with the conceptual tools of topology but his project did not find followers. Worse, no philosopher realized that Russell's sketch of a topological logical analysis had long been superseded by the ongoing evolution of topology. It never occurred to the mainstream philosophers of science that meanwhile mathematicians had produced much better topological tools than those that Russell had vaguely adumbrated. Topological and geometrical methods in philosophy of science showed up again only much later, and in a context quite unrelated to Russell's original project.

\section{THe RETURN OF MATHEMATICAL METHODS IN PHILOSOPHY OF SCIENCE}

Russell's attempt to introduce topological methods in philosophy of science for the logical analysis of philosophical and scientific notions remained unsuccessful. Under the reign of a reductionist logical philosophy mathematics, and a fortiori, geometry and topology, was doomed to be considered as irrelevant as an object and as a tool of philosophy of science:

(i) Being allegedly reducible in one way or other to logic, mathematics ceased to be an interesting object for the investigations of philosophy of science in its own right. Rather, from the perspective of logical philosophy of science, the only philosophically interesting area of mathematics was its logical foundation. The huge rest of "real mathematics" was considered as philosophically uninteresting,

21 See Thomas Mormann, "Russell's Many Points", in: A. Hieke and H. Leitgeb (Eds.), Reduction, Abstraction, Analysis, Proceedings of the 31th International Wittgenstein Symposium in Kirchberg 2008, pp. 239-258. 2009. 
being relevant only for mathematicians or those who were concerned with its applications of mathematics.

(ii) From the perspective of a strictly logical philosophy of science any project to use mathematics as a tool for philosophy of science made no sense. Tapping the conceptual sources of geometry and topology for understanding and elucidating the structure and the function of empirical theories seemed pointless. Rather, the only legitimate tool for philosophy of science was logic.

Through the decades the conceptual limitations of a strictly logical approach to philosophy of science became more and more visible. Even an arch logical empiricist such as Carnap came to admit that that logic of science might not be everything that philosophy of science had to say about science. He therefore proposed a kind of division of labour that proposed to complement the purely logical studies of science by other kind of investigations that dealt with the non-logical aspects of the sciences, for instance, history, sociology and psychology of science. Whether this plan is convincing need not be discussed here. Rather, I'd like to point out that also in this more liberal conception of philosophy of science the monopoly of logic for the study of the formal structure of science remained intact. That is to say, the tool for dealing with the formal structure of scientific theories continued to be logic and logic alone.

This contention, however, gradually lost unanimous agreement. Van Fraassen hails Patrick Suppes to have been the first who envisaged another way of dealing with the formal structure of science by questioning the basic assumption of received philosophy of science. More precisely, he diagnoses the fundamental error as having put too much emphasis on matters linguistic:

The mistake, I think, was to confuse a theory with the formulation of a theory in a particular language. The first to turn the tide was Patrick Suppes with his well-known slogan: the correct tool for philosophy of science is mathematics, not metamathematics. This happened in the 1950 s - bewitched by the wonders of logic and the theory of meaning, few wanted to listen. $^{22}$

In the decades after the 1950s the "semantic approach" in philosophy of science gained momentum. This is not to say that it could establish itself as a new unique orthodoxy. After all, Suppes's general recommendation to replace logic by mathematics as the basic tool of philosophy of science could be interpreted in many different ways - and indeed it was.

Suppes himself preferred a set-theoretical approach that conceived of scientific theories as set-theoretical structures. More precisely, he proposed to describe empirical theories such as mechanics or optics in terms of set-theoretical predicates in an analogous way as from a set-theoretical perspective a mathematical theory such as the theory of groups may be described in terms of the set-theoretical predicate "... is a group structure". Others, such as van Fraassen and Giere pre-

22 Van Fraassen, Laws of Symmetry, op. cit., pp. 221-222. 
ferred a more geometrical account that reconstructed empirical theories essentially in terms of families of models or representations basically characterized by geometrical or topological structures, to wit, state spaces or phase spaces as the basic means for spatial representations in a generalized sense. ${ }^{23}$

Theories offer something like conceptual spaces, patterns for spatial activities, or maps. Having a theory is having a map that can be used to guide one's actions. Topology, as a general theory of space, investigates the structure of these generalized spaces. As long as one sticks to a narrow conception of (Euclidean) space this spatial characterization of a theory is doomed to remain vague and metaphorical, since clearly the "spaces" that are used in the various theoretical representations of science are not Euclidean ones. Here topology comes to the rescue, since it provides an ample spectrum of thoroughly analysized spatial concepts that can be used for this purpose.

\section{Conclusion}

Although in a short paper like this we had to leave out many details, it should have become clear that the philosophical vicissitudes of topology in $20^{\text {th }}$ century philosophy of science offer a rich and multi-facetted agenda for history of philosophy of science that deserves further in-depth investigations. In particular the question why in the beginnings of the last century geometry lost its privileged status in philosophy and couldn't pass it on to topology requires further investigations. A too quick and simplistic answer would be that topology did not appear on the radar of philosophy because it was too technical and inaccessible a discipline for philosophers to squeeze some philosophical juice out of it. This answer is not convincing. Philosophy of science was often prepared to invest a lot of conceptual effort to come to terms with the intricacies of modern formal logic - and it is not always clear whether this was worth all the effort. Many examples show that philosophy of science did not shy away from considerable technical labor to come to terms with, say, quantum theory or relativity theory.

In contrast, philosophy of mathematics succumbed to the vice of elementarism or fundamentalism, as one may call it. Philosophers of mathematics, who subscribed to this doctrine located the philosophical relevance of mathematics entirely in its foundations, be they be claimed to be of a logical or set-theoretical nature or of any other kind. Consequently, topology and other advanced areas of mathematics disappeared from the agenda of philosophy of science. Such an attitude starkly contrasted with that of philosophy of the empirical sciences.

Recently the situation has changed again. After logic had lost its monopoly in philosophy of science, a new "mathematical philosophy of science" has begun to

23 Ron Giere, Explaining Science. A Cognitive Approach. Chicago: University of Chicago Press 1988, p. 20. 
gain momentum. At least partially this new mathematical philosophy of science is informed by ideas that have a close affinity to geometry and topology. In other words, after having overcome the neglect from classical logic-centered philosophy of science the philosophical vicissitudes of topology and geometry continue to be an interesting topic on the agenda of history of philosophy of science.

Acknowledgment: Research for this this work is part of the research project FFI 2009-12882 funded by the Spanish Ministry of Science and Education.

Department of Logic and Philosophy of Science University of the Basque Country (UPV/EHU)

P.O. Box 1249

20080, Donostia-San Sebastian

Spain

ylxmomot@ehu.es 